\title{
Wilderness Medical Society Practice Guidelines for the Out-of-Hospital Evaluation and Treatment of Accidental Hypothermia
}

Ken Zafren, MD; Gordon G. Giesbrecht, PhD; Daniel F. Danzl, MD; Hermann Brugger, MD; Emily B. Sagalyn, MD, MPH; Beat Walpoth, MD; Eric A. Weiss, MD; Paul S. Auerbach, MD; Scott E. McIntosh, MD, MPH; Mária Némethy, MD; Marion McDevitt, DO, MPH; Jennifer Dow, MD; Robert B. Schoene, MD; George W. Rodway, PhD, APRN; Peter H. Hackett, MD; Brad L. Bennett, PhD; Colin K. Grissom, MD

From the Division of Emergency Medicine, Department of Surgery, Stanford University School of Medicine, Stanford, CA (Drs Zafren, Weiss, and Auerbach); the International Commission for Mountain Emergency Medicine (ICAR MEDCOM) (Drs Zafren and Brugger); the Faculty of Kinesiology and Recreation Management, Departments of Anesthesia and Emergency Medicine, University of Manitoba, Winnipeg, Canada (Dr Giesbrecht); the Department of Emergency Medicine, University of Louisville, School of Medicine, Louisville, KY (Dr Danzl); the European Academy Institute of Mountain Emergency Medicine, Bolzano, Italy (Dr Brugger); the University of Nevada School of Medicine, Reno, NV (Dr Sagalyn); the Service of Cardiovascular Surgery, University Hospital of Geneva, Geneva, Switzerland (Dr Walpoth); the Division of Emergency Medicine, University of Utah, Salt Lake City, UT (Drs McIntosh, Némethy, and McDevitt); the Alaska Regional Hospital, Anchorage, AK (Dr Dow); Denali National Park and Preserve, AK (Dr Dow); the University of Washington, Seattle, WA (Dr Schoene); the Division of Health Sciences, University of Nevada, Reno, NV (Dr Rodway); the Division of Emergency Medicine, Altitude Research Center, University of Colorado School of Medicine, Denver, CO (Dr Hackett); the Institute for Altitude Medicine, Telluride, CO (Dr Hackett); the Military \& Emergency Medicine Department, F. Edward Hébert School of Medicine, Uniformed Services University of the Health Sciences Bethesda, MD (Dr Bennett); and the Division of Pulmonary and Critical Care Medicine, Intermountain Medical Center and the University of Utah, Salt Lake City, UT (Dr Grissom).

\begin{abstract}
To provide guidance to clinicians, the Wilderness Medical Society (WMS) convened an expert panel to develop evidence-based guidelines for the out-of-hospital evaluation and treatment of victims of accidental hypothermia. The guidelines present the main diagnostic and therapeutic modalities and provide recommendations for the management of hypothermic patients. The panel graded the recommendations based on the quality of supporting evidence and the balance between benefits and risks/burdens according the criteria published by the American College of Chest Physicians. The guidelines also provide suggested general approaches to the evaluation and treatment of accidental hypothermia that incorporate specific recommendations.
\end{abstract}

Key words: accidental hypothermia, hypothermia, rewarming, resuscitation, wilderness medicine, avalanche, cold

\section{Introduction}

Accidental hypothermia is defined as an unintentional drop in core temperature to $35^{\circ} \mathrm{C}$ or below. Accidental hypothermia caused by environmental exposure can occur during any season, even in temperate or tropical climates. Cold and wet environments pose the greatest risk. Accidental hypothermia can occur in people participating in outdoor work and recreation, including wilderness travelers. Accidental hypothermia has been a disease of wars and other disasters throughout history. In addition to occurring in wilderness environments, hypothermia is associated with urban homelessness and with the use of alcohol and other substances, including recreational and therapeutic drugs. Hypothermia can occur

Corresponding author: Ken Zafren, MD, 10181 Curvi Street, Anchorage, AK 99507 (e-mail: zafren@alaska.com). during resuscitation in emergency settings (iatrogenic hypothermia). Hypothermia can accompany trauma, sepsis, diseases that decrease metabolic rate such as hypoendocrine states, and diseases that affect thermoregulation such as cancer or stroke. Therapeutic hypothermia, which is induced for neuroprotection in cardiac arrest patients who do not regain consciousness after return of spontaneous circulation, is beyond the scope of this review.

Hypothermia occurs as a result of net heat loss from the body. Heat can be lost or gained by conduction, convection, and radiation and lost through evaporation. Conduction is the direct transfer of heat from warmer to cooler objects that are in contact with each other. Convection is the transfer of heat to or from a gas or a liquid that is in motion. Radiation is the transfer of heat in the form of electromagnetic energy between 2 objects that are visible to each other. Evaporation is the loss of heat by vaporizing liquid—usually water-in 
sweat, on the skin, or in clothing, or from insensible losses from the skin or from respiration.

The human body attempts to maintain a core temperature of $37^{\circ} \mathrm{C} \pm 0.5^{\circ} \mathrm{C}$. The thermoregulatory control center in the hypothalamus receives input from central and peripheral thermal receptors. The integrated thermal signal triggers autonomic reflexes that control whether cooling responses, such as vasodilation or sweating, or warming responses, such as vasoconstriction or shivering, are initiated. ${ }^{1}$ Peripheral blood flow is also partly regulated by local skin temperature.

Humans originated in the tropics with limited physiologic means to avoid developing hypothermia. Exercise and shivering can raise the metabolic rate to prevent hypothermia if nutritional reserves and insulation are adequate, but the benefit may be limited by environmental conditions. Prevention of hypothermia in humans mostly depends on behavior, especially wearing insulating clothing and using shelter.

\section{Methods}

The Wilderness Medical Society (WMS) convened an expert panel to develop evidence-based guidelines for the prevention and out-of-hospital diagnosis and treatment of victims of accidental hypothermia. Panelists were selected by the WMS on the basis of clinical or research experience with hypothermia. The panel generated a set of questions (Figure 1) to define the most significant areas of interest and identified relevant articles with a key word search of the MEDLINE database. Key words were hypothermia, accidental hypothermia, wilderness hypothermia, avalanche, shivering, and rewarming. The literature search included related and secondary references. The panel considered only peer-reviewed randomized controlled trials, observational studies, case series, and case reports related to evaluation and treatment of accidental hypothermia.

The panel assessed the level of evidence supporting each diagnostic and therapeutic modality. Conclusions from review articles were not used in the formulation of recommendations, but the guidelines cite review articles when necessary to provide background information.

The panel used a consensus approach to develop recommendations regarding each evaluation technique and intervention and its role in management. The panel graded each recommendation on the basis of the quality of supporting evidence and the balance between the benefits and risks or burdens, according to the criteria of the American College of Chest Physicians (Table 1). ${ }^{2}$

\section{Pathophysiology of Hypothermia}

The primary physiologic effects of tissue cooling are decreased resting metabolism and inhibition of central and peripheral neurologic function. During the initial stages of cooling of a neurologically intact victim, secondary responses to skin cooling predominate. ${ }^{1}$ Shivering thermogenesis, triggered by skin cooling even at a core temperature of $37^{\circ} \mathrm{C}$, results in increased metabolism because of the work of shivering and increased ventilation, cardiac output, and mean arterial pressure. $^{3}$ These parameters increase initially as core temperature decreases to approximately $32^{\circ} \mathrm{C}$, then decrease with further decreases in core temperature. ${ }^{1}$ Shivering ceases at and below a core temperature of approximately $30^{\circ} \mathrm{C} .^{4}$ Once this occurs, metabolism decreases with decreases in core temperature.

Clinical manifestations of accidental hypothermia relate predominantly to cerebral and cardiorespiratory effects. Brain activity begins to decline at a core temperature of approximately $33^{\circ} \mathrm{C}$ to $34^{\circ} \mathrm{C}$ and continues to decline with further cooling. ${ }^{5,6}$ Cooling of the brain leads to irritability, confusion, apathy, poor decision-making, lethargy, somnolence, and eventually coma. Brain cooling decreases cerebral oxygen requirements. ${ }^{7}$ This provides temporary protection during anoxic conditions such as cold-induced cardiac standstill and cold water drowning. Cold stress reduces circulating blood volume as a result of a combination of coldinduced diuresis, extravascular plasma shift, and inadequate fluid intake. ${ }^{8}$ As the heart cools below $30^{\circ} \mathrm{C}$, cardiac output decreases markedly and bradycardia usually occurs. Abnormalities in electrical conduction lead to dysrhythmias such as premature atrial and ventricular contractions, atrial fibrillation, and ventricular fibrillation (VF). ${ }^{9}$ Below $28^{\circ} \mathrm{C}$, the heart is susceptible to VF, which can be triggered by acidosis, hypocarbia, hypoxia, or movement. ${ }^{1}$ Decreased ventilatory response to carbon dioxide leads to hypoventilation and respiratory acidosis. ${ }^{10}$

\section{Field Assessment}

\section{CLASSIFICATION OF HYPOTHERMIA}

Most guidelines now use a standard classification of hypothermia based on core temperature. Hypothermia is classified as mild, $35^{\circ} \mathrm{C}$ to $32^{\circ} \mathrm{C}$; moderate, $32^{\circ} \mathrm{C}$ to $28^{\circ} \mathrm{C}$; or severe, $<28^{\circ} \mathrm{C}^{1,11-13}$ Some experts have advocated a further category, profound hypothermia, $<24^{\circ} \mathrm{C}^{12}$ or $<20^{\circ} \mathrm{C}^{1}{ }^{1}$ The chance of survival seems to be much lower in this range, probably because of a high likelihood of cardiac arrest. Although it is helpful to use core temperature to classify hypothermia, there is great variation among individuals in response to core temperature, as with any other physiologic parameter. Measuring core temperature is not always feasible in the out-of-hospital environment. ${ }^{14}$ 
Wilderness Medical Society Practice Guidelines for the

Pre-hospital Evaluation and Treatment of Accidental Hypothermia

\section{QUESTIONS}

\section{FIELD ASSESSMENT}

How should the level of hypothermia be classified?

What is the best way to measure core temperature?

\section{PREHOSPITAL TREATMENT}

What is the best initial treatment for a cold patient who may be hypothermic?

What is the best treatment for a cold patient who is not hypothermic or for a patient with mild hypothermia in the field?

What is the safest way to handle a patient with moderate to severe hypothermia in the field?

What is the best treatment for moderate to severe hypothermia?

When should a hypothermic patient without signs of life be resuscitated?

When should rescuers start cardiopulmonary resuscitation (CPR) on a hypothermic

patient?

When and how should a hypothermic patient be defibrillated?

What is the best method for giving CPR to a hypothermic patient?

What is the best way to manage the airway in a severely hypothermic patient?

What is the best way to obtain vascular access in a hypothermic patient?

What is the best way to manage fluids in a hypothermic patient?

What is the role of Advanced Life Support (ALS) drugs in a hypothermic patient?

Is there a role for transcutaneous cardiac pacing in a hypothermic patient?

How should atrial dysrhythmias be managed during rewarming for a hypothermic patient?

\section{TRANSPORT/TRIAGE}

How should the destination hospital be determined for a hypothermic patient? How can serum potassium be used to determine if CPR should be continued on a hypothermic patient?

Figure 1. Questions considered by the authors.

\section{Factors to guide treatment}

The standard classification of hypothermia by core temperature correlates with the status of the thermoregulatory system. From $35^{\circ} \mathrm{C}$ to $32^{\circ} \mathrm{C}$, thermoregulatory shivering control is functional and increases as core temperature decreases. ${ }^{15}$ Shivering generally becomes less effective with further cooling, although it can still be strong at $31^{\circ} \mathrm{C} .{ }^{4}$ Below $32^{\circ} \mathrm{C}$, thermoregulation becomes less effective, and rewarming is possible only with addition of exogenous heat. As core temperature decreases below $32^{\circ} \mathrm{C}$, the level of consciousness decreases further. Below $28^{\circ} \mathrm{C}$, most patients are unconscious and not shivering. There is a high risk of VF or asystole as a result of hypothermia. ${ }^{16}$

Recommendation. The key factors to guide treatment are level of consciousness, shivering intensity, and cardiovascular stability, based on blood pressure and cardiac rhythm (Figure 2). Core temperature can provide additional helpful information (panel consensus). 
Table 1. ACCP classification scheme for grading evidence and recommendations in clinical guidelines

\begin{tabular}{|c|c|c|c|}
\hline Grade & Description & Benefits vs risks and burdens & $\begin{array}{l}\text { Methodological quality of } \\
\text { supporting evidence }\end{array}$ \\
\hline $1 \mathrm{~A}$ & $\begin{array}{l}\text { Strong recommendation, } \\
\text { high-quality evidence }\end{array}$ & $\begin{array}{l}\text { Benefits clearly outweigh risks } \\
\text { and burdens or vice versa }\end{array}$ & $\begin{array}{l}\text { RCTs without important } \\
\text { limitations or overwhelming } \\
\text { evidence from observational } \\
\text { studies }\end{array}$ \\
\hline $1 \mathrm{~B}$ & $\begin{array}{l}\text { Strong recommendation, } \\
\text { moderate-quality evidence }\end{array}$ & $\begin{array}{l}\text { Benefits clearly outweigh risks } \\
\text { and burdens or vice versa }\end{array}$ & $\begin{array}{l}\text { RCTs with important limitations } \\
\text { or exceptionally strong evidence }\end{array}$ \\
\hline $1 \mathrm{C}$ & $\begin{array}{l}\text { Strong recommendation, low-quality } \\
\text { or very low quality evidence }\end{array}$ & $\begin{array}{l}\text { Benefits clearly outweigh risks } \\
\text { and burdens or vice versa }\end{array}$ & $\begin{array}{l}\text { from observational studies } \\
\text { Observational studies or case } \\
\text { series }\end{array}$ \\
\hline $2 \mathrm{~A}$ & $\begin{array}{l}\text { Weak recommendation, } \\
\text { high-quality evidence }\end{array}$ & $\begin{array}{l}\text { Benefits closely balanced } \\
\text { with risks and burdens }\end{array}$ & $\begin{array}{l}\text { RCTs without important } \\
\text { limitations or overwhelming } \\
\text { evidence from observational } \\
\text { studies }\end{array}$ \\
\hline $2 \mathrm{~B}$ & $\begin{array}{l}\text { Weak recommendation, } \\
\text { moderate-quality evidence }\end{array}$ & $\begin{array}{l}\text { Benefits closely balanced with } \\
\text { risks and burdens }\end{array}$ & $\begin{array}{l}\text { RCTs with important limitations } \\
\text { or exceptionally strong } \\
\text { evidence from observational }\end{array}$ \\
\hline $2 \mathrm{C}$ & $\begin{array}{l}\text { Weak recommendation, low-quality } \\
\text { or very low quality evidence }\end{array}$ & $\begin{array}{l}\text { Uncertainty in the estimates of } \\
\text { benefits, risks and burden; } \\
\text { benefits, risk and burden may } \\
\text { be closely balanced }\end{array}$ & $\begin{array}{l}\text { studies } \\
\text { Observational studies or case } \\
\text { series }\end{array}$ \\
\hline
\end{tabular}

RCT, randomized controlled trial.

Source: Guyatt G, Gutterman D, Baumann MH, et al. Grading strength of recommendations and quality of evidence in clinical guidelines: report from an American College of Chest Physicians task force. Chest. 2006;129:174-181.

\section{Some patients are cold, but not hypothermic}

Because shivering is triggered by skin cooling as a mechanism for preventing hypothermia, patients can be cold and shivering but not hypothermic. A cold, shivering patient with a core temperature $>35^{\circ} \mathrm{C}$ is cold stressed, but not hypothermic. If temperature measurement is not possible, clinical judgment may be helpful to distinguish whether a patient is hypothermic or cold stressed but not hypothermic. For example, a patient who was not cold before being briefly immersed in cold water may be shivering, but will not be hypothermic. Many alert, shivering patients who are well nourished and not exhausted are not hypothermic.

Recommendation. A patient who is shivering but able to function well and to care for himself or herself is unlikely to be hypothermic. A patient who is shivering, becoming incapacitated, and having difficulty caring for himself or herself is likely to be hypothermic. If there is any doubt, assume that the patient is hypothermic (panel consensus).

\section{Alternate classification of hypothermia}

The American Heart Association (AHA) 2010 Guidelines propose an alternative classification of hypothermia: mild $\left(>34^{\circ} \mathrm{C}\right)$, moderate $\left(34^{\circ} \mathrm{C}-30^{\circ} \mathrm{C}\right)$, and severe $\left(<30^{\circ} \mathrm{C}\right) .{ }^{17}$ Below $30^{\circ} \mathrm{C}$, defibrillation is less likely to be successful than above $30^{\circ} \mathrm{C}$.

Recommendation. The AHA scheme is not as useful as the standard classification because it changes the widely accepted definition of hypothermia and emphasizes response to defibrillation rather than physiologic changes (panel consensus).

\section{Field classification of hypothermia: the Swiss system}

The Swiss hypothermia classification was developed to help rescuers estimate core temperature by observing clinical signs. ${ }^{12}$ Because there is great variability among individuals in response to cold, estimating core temperature on the basis of clinical signs is only an approximation. The stages of the Swiss hypothermia (abbreviated HT) grading system with descriptions and estimated core temperature are as follows:

- HT I-clear consciousness with shivering: $35^{\circ} \mathrm{C}$ to $32^{\circ} \mathrm{C}$

- HT II-impaired consciousness without shivering: $32^{\circ} \mathrm{C}$ to $28^{\circ} \mathrm{C}$

- HT III-unconscious: $28^{\circ} \mathrm{C}$ to $24^{\circ} \mathrm{C}$

- HT IV-apparent death: $24^{\circ} \mathrm{C}$ to $13.7^{\circ} \mathrm{C}$

- HT V-death as a result of irreversible hypothermia: $<13.7^{\circ} \mathrm{C} ?\left(<9^{\circ} \mathrm{C} \text { ? }\right)^{12}$ 


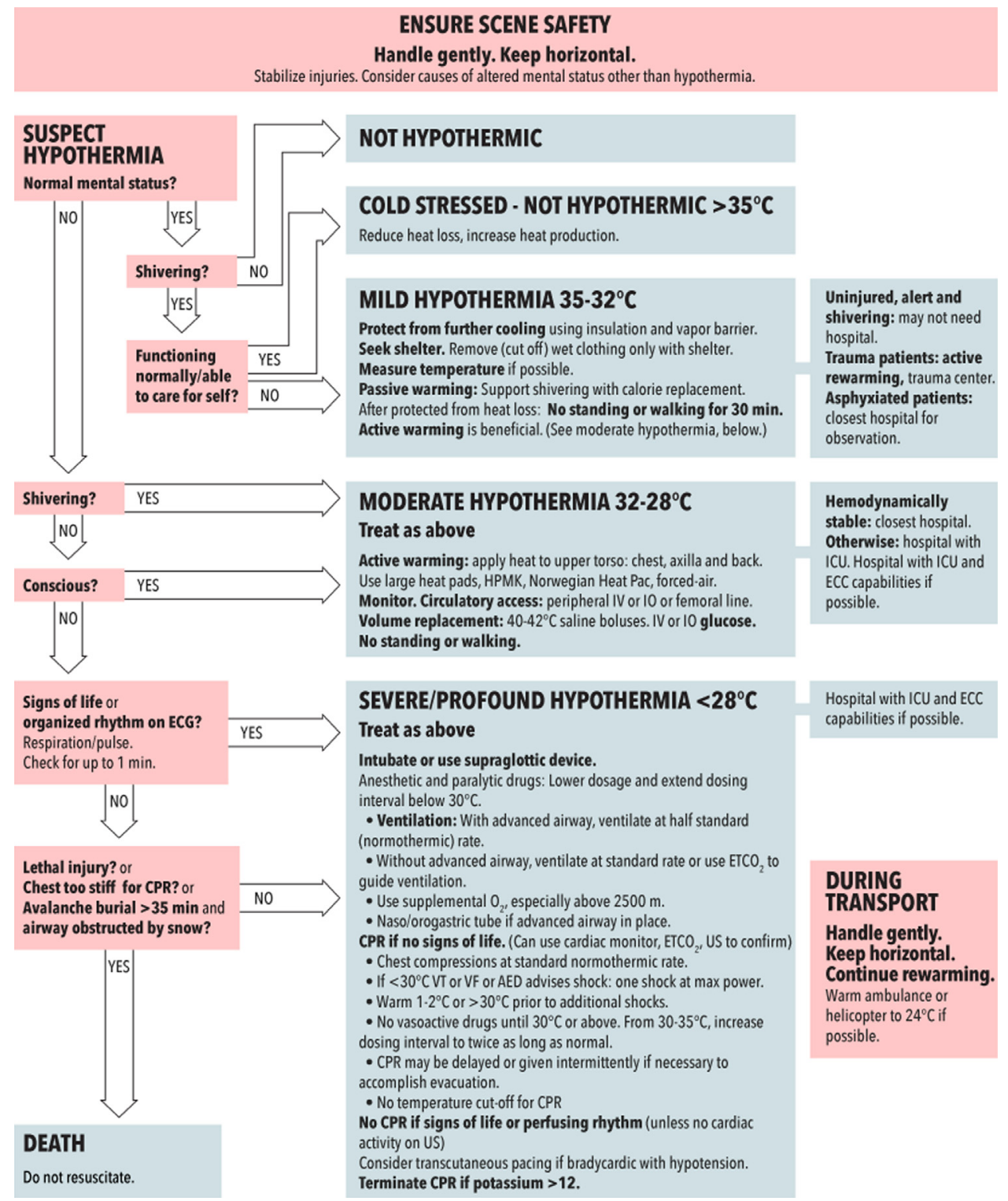

Figure 2. Recommendations for out-of-hospital evaluation and treatment of accidental hypothermia. ECG indicates electrocardiogram; CPR, cardiopulmonary resuscitation; HPMK, Hypothermia Prevention Management Kit; IV, intravenous; IO, intraosseous; ETCO ${ }_{2}$, end-tidal carbon dioxide; VT, ventricular tachycardia; VF, ventricular fibrillation; AED, automatic external defibrillator; US, ultrasound; ICU, intensive care unit; ECC, extracorporeal circulation.

A limitation of this system is that individuals vary in physiologic response to hypothermia. Shivering may be maximal at $32^{\circ} \mathrm{C}$ to $33^{\circ} \mathrm{C}$, may continue at $31^{\circ} \mathrm{C}$, and may not cease until core temperature drops to approximately $30^{\circ} \mathrm{C}$. A shivering patient with impaired consciousness and a core temperature below $32^{\circ} \mathrm{C}$ should be treated for moderate hypothermia. It would be hazardous for rescuers to focus on shivering rather than on impaired consciousness and treat for mild hypothermia. There are also many case reports of hypothermic patients with vital signs who had core temperatures below $24^{\circ} \mathrm{C}{ }^{18-22}$ These individuals are very susceptible to ventricular fibrillation. The HT numbering system is difficult to remember. It is easier to refer to mild, moderate, severe, and profound hypothermia.

Recommendation. Because the temperature ranges to which the HT grades are meant to correspond are the same as the standard classification, rescuers should refer to mild, moderate, severe, and profound hypothermia $\left(<24^{\circ} \mathrm{C}\right)$ on the basis of their clinical observations, remembering that shivering can occur below $32^{\circ} \mathrm{C}$, usually with altered mental status, and that patients can 
have detectable vital signs with core temperatures below $24^{\circ} \mathrm{C}$ (panel consensus).

Associated conditions complicating the field classification of hypothermia

In addition to hypothermia, many conditions can cause altered mental status and a decreased level of consciousness. Conditions, such as sepsis and severe trauma, that decrease physiologic reserves decrease or abolish shivering. ${ }^{23}$ Many drugs and medications also suppress shivering. ${ }^{24}$

Recommendation. Clinicians should consider causes other than hypothermia to explain altered mental status or lack of shivering that does not correlate with the measured core temperature or by a history of minimal cold exposure (panel consensus).

\section{MEASUREMENT OF CORE TEMPERATURE}

\section{Esophageal temperature}

The most accurate minimally invasive method of measuring core temperature is esophageal temperature, with the probe inserted into the lower third of the esophagus. ${ }^{25}$ The degree of accuracy afforded by esophageal temperature monitoring is helpful to guide treatment of patients with moderate or severe hypothermia. Placement of an esophageal probe may cause vomiting and aspiration. Before placing an esophageal probe it is best to protect the airway with an endotracheal tube or supraglottic device. The use of heated humidified oxygen may result in a falsely elevated esophageal temperature if the esophageal probe is not inserted into the lower third of the esophagus, an average of $24 \mathrm{~cm}$ below the larynx in adults. ${ }^{1}$ Heated humidified oxygen does not significantly raise the temperature measured by a properly inserted esophageal probe. ${ }^{26-28}$ Esophageal probes that do not have markings can be measured visually against the patient and marked to ensure the correct depth of insertion.

Recommendation. In a patient whose airway has been secured with an endotracheal tube or with a supraglottic airway that has a port for placing a gastric tube, use esophageal temperature monitoring with the esophageal temperature probe inserted into the lower third of the esophagus (1C).

\section{Epitympanic temperature}

Epitympanic (ear canal) temperature, measured using a soft probe with a thermistor in proximity to the tympanic membrane, reflects carotid artery temperature. ${ }^{29}$ Epitympanic thermometers should not be confused with the more common and much less accurate infrared "tympanic" thermometers. In patients with adequate cardiac output, epitympanic temperature reflects core temperature. Epitympanic temperature can be lower than esophageal temperature during low-flow (decreased cardiac output) or no-flow (cardiac arrest) states. ${ }^{24}$ In outof-hospital settings, care must be taken to insulate the ear canal from the environment. In cold ambient temperatures, epitympanic temperature may be falsely low, especially if the external auditory canal is blocked by cerumen, filled with snow, or not adequately sealed and properly covered with an isolating "cap." 29 Epitympanic thermometers for use in the operating room are not suitable for field use because they are not designed for use in cold environments.

Recommendation. Use an epitympanic thermometer designed for field conditions with an isolating ear cap in a patient whose airway has not been secured by endotracheal intubation or a supraglottic airway or in a patient with a secured airway if an esophageal probe is not available (1C).

\section{Rectal temperature in the field}

The use of rectal thermometers is not advisable before the patient has been removed from the cold environment because the patient must be further exposed, increasing heat loss and potentially worsening hypothermia.

Recommendation. Rectal temperature should not be measured in the field until the patient is in a warm environment (1C).

\section{Oral temperature}

Oral temperatures are useful only to rule out hypothermia. Nonelectronic thermometers are typically unable to measure temperatures below $35.6^{\circ} \mathrm{C}$. If mercury or alcohol thermometers are used to diagnose hypothermia, they must be special "low reading" thermometers. ${ }^{1}$

Recommendation. Use oral temperature measurement with a thermometer (electronic or liquid-filled) that can read below $35^{\circ} \mathrm{C}$ only to rule out hypothermia (1A).

\section{Rectal and bladder temperatures during rewarming}

During rewarming, measured temperatures other than esophageal and epitympanic temperature, including rectal and bladder temperatures, lag behind core temperature changes by as much as an hour and can give the false impression that the patient is still cooling., ${ }^{3,8}$ Because changes in rectal and bladder temperature lag behind changes in heart temperature, rectal and bladder temperature overestimate heart temperature during 
cooling and underestimate heart temperature during rewarming.

Recommendation. Monitor rectal or bladder temperature during rewarming of an unconscious patient only if an esophageal or epitympanic probe is not available. If rectal or bladder temperature is used for monitoring during rewarming, allow for inaccuracy owing to the time lag behind core temperature changes $(1 \mathrm{~A})$.

"Temporal artery" thermometer

So-called temporal artery thermometers, used on the skin surface, do not provide accurate temperature measurements in hypothermia. ${ }^{30}$

Recommendation. Do not use a temporal artery thermometer in a possibly hypothermic patient (1C).

\section{Heat flux thermometer}

A noninvasive heat flux or "double sensor" thermometer is currently under development. ${ }^{31}$ This technology, which combines a skin temperature sensor with a heat flux sensor, correlates well with esophageal temperature in operative and intensive care unit settings. ${ }^{32}$

Recommendation. Because this technology has not been validated in field settings, no recommendation can be made at this time.

\section{OUT-OF-HOSPITAL TREATMENT}

\section{Safety of the rescuers}

Safety of the rescuers is the first priority during rescue. The scene may be unsafe to enter, or the safety officer in a rescue may allow only very brief entry. Unless there are obvious fatal injuries, rescuers might need to move the patient to a safe place before making a decision to resuscitate.

Recommendation. The decision to rescue or to resuscitate a potentially severely hypothermic patient should only be made after the scene is secure and safe for the rescuers to enter and make an evaluation (1A).

After safety of rescuers has been assured, the priorities in out-of-hospital treatment of a hypothermic patient who is not in cardiac arrest are to avoid causing cardiovascular collapse during rescue, to prevent a further decrease in core temperature (afterdrop), and to rewarm the patient in a safe manner. If a hypothermic patient is in cardiac arrest, rescuers should initiate resuscitation, if indicated.

\section{Core temperature afterdrop}

Core temperature afterdrop refers to continued core cooling after removal from cold exposure. Afterdrop is caused by a combination of conductive heat loss from the warmer core to cooler peripheral tissue and convective heat loss from blood as a result of increased flow to cooler tissue and subsequent return to the central circulation and heart. ${ }^{33-35}$ The convective component transfers more heat and, unlike the conductive component, is affected by the method of rewarming. In a hypothermia victim, peripheral tissue is colder than the heart. Increase in blood flow to the cold periphery with movement or rewarming of the extremities results in increased volume and cooling of blood flowing to the cold periphery and returning to the heart. This increases cardiac work and decreases core temperature.

Afterdrop may be clinically important in victims who are at the thresholds of moderate to severe hypothermia because they are susceptible to cardiovascular instability with a small further drop in core (heart) temperature. Afterdrop of as much as $5^{\circ} \mathrm{C}$ to $6^{\circ} \mathrm{C}$ has been reported in hypothermic patients. ${ }^{21,36,37}$

\section{Circumrescue collapse}

Circumrescue collapse refers to syncope or sudden death occurring in victims of cold-water immersion just before, during, or after rescue and removal from water. ${ }^{38}$ Circumrescue collapse can be caused by lifethreatening hypotension or by sudden onset of VF. ${ }^{3}$

The act of removing a victim from water decreases hydrostatic pressure, ${ }^{3}$ which is normally greatest around the legs. Removing hydrostatic pressure allows blood to pool in dependent areas, causing decreased blood return with resultant hypotension or cardiovascular collapse. A cold heart may not be able to compensate for decreasing blood pressure by increasing cardiac output. Blood that does return from dependent areas will be cooled and will contribute to core temperature afterdrop. Afterdrop is increased if the victim has to perform work to assist in rescue, for example, by having to climb a ladder onto a boat. ${ }^{38,39}$ Mechanical stimulation of the heart during rescue and extrication, combined with afterdrop and acidosis, may precipitate $\mathrm{VF}^{40}$

When rescue is imminent, mental relaxation in conscious patients may be associated with decreased catecholamine release, causing decreased blood pressure with loss of consciousness and drowning. ${ }^{40}$ Circumrescue collapse has also been described in terrestrial rescue situations. ${ }^{18,41}$

\section{Handling of a hypothermic patient during rescue}

Keeping the patient in a horizontal position mitigates the effects of decreased hydrostatic pressure during rescue. ${ }^{38}$ Avoiding physical effort protects against afterdrop. ${ }^{39}$ 
Avoiding mental relaxation may help maintain catecholamine stimulus.

Recommendation. Rescuers should keep a hypothermic patient horizontal, especially during rescue from water or from a crevasse (1B) and should limit physical effort by the patient during rescue (1B). A conscious patient should be encouraged to be vigilant and focus on survival (1C).

\section{Gentle handling to prevent ventricular fibrillation}

Hypothermia lowers the threshold for ventricular fibrillation, especially at core temperatures below $28^{\circ} \mathrm{C} .{ }^{1}$ Movement or significant warming of the extremities, as with warm-water immersion, increases blood flow to colder tissues, cooling blood that then returns to the core circulation. This has the potential to cool the heart, increasing the risk of VF. ${ }^{16,42,43}$ Additional blood return may also cause an increased load on a heart that is already pumping ineffectively.

Recommendation. Handle a hypothermic patient gently and continue to keep the patient horizontal (1B). Avoid any disturbance, especially movement of the extremities that might precipitate VF (1B). Once the patient is in a warm environment, clothes should be cut off rather than removed manually (1B).

\section{Protection from further heat loss}

After rescue, the next priority for the care of a hypothermic patient in the out-of-hospital setting is to maintain core temperature by preventing further heat loss.

Insulation protects from heat loss. Insulating materials, in addition to extra clothing, include blankets, quilts, sleeping bags, insulated pads, and bubble wrap. ${ }^{44,45}$ Bubble wrap is an effective vapor barrier, but provides less insulation than the other materials. ${ }^{44,45}$ A large amount of heat can be lost to the ground by conduction. ${ }^{46}$ Significant heat can also be lost from the head and neck because of the required opening for the face to allow breathing. ${ }^{46,47}$

A vapor barrier that protects against convective and evaporative cooling can be made from bubble wrap, tarp, sheet of plastic, reflective blanket, or garbage bag with a hole cut out for the face. The vapor barrier should also protect the insulation from becoming wet. The vapor barrier layer is usually placed outside of all other layers, ${ }^{45,48}$ but can be placed between wet clothing and the outer insulating layers in dry conditions.

Extra insulation can compensate for the absence of a windproof layer or vapor barrier. ${ }^{48} \mathrm{~A}$ combined method that incorporates insulation inside a vapor barrier is effective. ${ }^{45}$
Recommendations. Protect from further cooling by using insulation and a vapor barrier until the patient has reached a warm environment, such as the interior of an ambulance. Remove wet clothes, preferably by cutting them off, only when the patient has been protected from the cold (1C). Take special care to insulate the patient from the ground (eg, with sleeping pads) to protect from conductive heat loss and also to protect the head and neck by closing the area around the face as effectively as possible (1C).

\section{Protection from windy conditions}

In windy conditions, a windproof layer, ideally a vapor barrier, provides substantial protection from convective heat loss. ${ }^{44}$

Recommendation. Use an outer windproof layer to protect the patient from wind and especially from rotor wash when loading or unloading from a helicopter (1C).

\section{FIELD REWARMING}

Once a hypothermic patient has been protected from further heat loss, the next priority is to rewarm the patient. Because afterdrop can lead to hemodynamic instability and ventricular fibrillation, rewarming methods should minimize the afterdrop even at the cost of slower warming overall. It is important to limit afterdrop by limiting limb movement and by keeping the patient horizontal. Most patients with altered consciousness require active rewarming.

\section{Shivering}

Vigorous shivering can increase heat production by 5 to 6 times the resting metabolic rate and up to $50 \%$ of maximal metabolic rate. ${ }^{4,49}$ Shivering can raise core temperature $3^{\circ} \mathrm{C} / \mathrm{h}$ to $4^{\circ} \mathrm{C} / \mathrm{h},{ }^{24,50}$ but uses a large amount of energy, stresses the cardiovascular system, and causes the patient discomfort. ${ }^{16}$

Recommendation. Shivering is an effective method of rewarming a patient who is cold but not hypothermic or who is mildly hypothermic. The patient must have sufficient energy reserves to sustain shivering and must be adequately insulated from the environment to retain the heat that is generated $(1 \mathrm{~A})$.

\section{Calories to support shivering}

The traditional method of providing calories to support shivering is to give warm, sugar-containing drinks. Warm drinks do not themselves provide a clinically significant amount of heat, but carbohydrates provide calories to help fuel shivering. ${ }^{16}$ 
Recommendation. An alert patient who is shivering, and who is not at risk for aspiration, should receive high-carbohydrate liquids and food. Liquids and food may be warmed but should not be hot enough to cause burns (1C).

\section{Delay standing or walking}

Standing upright increases blood flow to and from the legs, worsening afterdrop and potentially decreasing blood pressure. ${ }^{25}$ Walking or other exercise generates additional heat but if initiated immediately after rescue, may cause a greater afterdrop in core temperature than if delayed. ${ }^{39}$

Recommendation. Initially, a hypothermic patient should not be allowed to stand or walk (1C).

\section{Delay exercise to protect against afterdrop}

Once a patient is protected from further heat loss and has adequate energy reserves, the most effective means of rescue may be for the patient to walk. Allowing the patient to shiver for 30 minutes, while insulated, before exercise should help to minimize afterdrop. ${ }^{39}$

Recommendation. A shivering patient who may be hypothermic should be kept as warm as possible, given calorie replacement, and observed for at least 30 minutes before exercising. The patient should be monitored closely. An alert patient may be allowed to stand. If the patient can stand without difficulty, exercise intensity should start low and increase gradually as tolerated (1C).

\section{Active external rewarming}

Field methods of external rewarming are useful in both shivering and nonshivering patients. Active (exogenous) rewarming methods, such as large electric heat pads or blankets, ${ }^{51}$ large chemical heat pads, ${ }^{52,53}$ warm water bottles ${ }^{54}$ and the Norwegian charcoal-burning HeatPac (Normeca, Loerenskog, Norway), ${ }^{16,51,55}$ provide significant heat. In a shivering patient, the added heat attenuates shivering heat production. This results in a rate of core rewarming similar to that produced by shivering, but has the advantages of increased comfort and decreased energy use with lower cardiac workload. In a nonshivering patient, added heat will warm the core, even if slowly, that would not have warmed spontaneously owing to reduced metabolic heat production. The HeatPac should be used with caution because it can generate potentially toxic levels of carbon monoxide (CO). ${ }^{28}$

Recommendations. Large heat pads should be used, if available (1B). Rewarming devices should be used in conjunction with vapor barriers and insulation (1C). The
HeatPac should only be used outdoors or with proper ventilation that is carefully monitored (1B).

\section{Body-to-body rewarming}

Body-to-body rewarming of a shivering patient with a warm person in a sleeping bag blunts the increase in shivering thermogenesis, resulting in rewarming rates no greater than shivering alone. ${ }^{50,51}$ Body-to-body rewarming may make the cold patient more comfortable as a result of decreased shivering, but at the cost of delaying evacuation.

Recommendation. Body-to-body rewarming can be used in mild hypothermia to increase patient thermal comfort if enough personnel are available and if it does not delay evacuation to definitive care (1B).

\section{Applying heat to the axillae, chest, and back}

External heat is most effective if concentrated on the axillae, chest, and back (in that order), which are the areas with the highest potential for conductive heat transfer. ${ }^{46}$ Upper torso rewarming is safer and more effective than extremity rewarming. ${ }^{56}$

Recommendations. Apply heat sources to the axillae, chest, and back. A large heat pad or blanket should be placed over the chest and, if large enough, extended into the axillae and under the back (1B). Additional heat, if available, can be applied to the neck if precautions are taken to prevent heat loss through any neck opening (1C). Avoid applying external heat to the extremities, although it is not necessary to insulate the arms from heat applied to the torso (1B).

\section{Hypothermia Prevention Management Kit (HPMK)}

The US military have developed the Hypothermia Prevention Management Kit (HPMK). This kit is composed of a Heat-Reflective Shell (HRS) and a ReadyHeat blanket with 4 chemical heat pads that sustain 6 hours of continuous heat. This ensemble was very effective at preventing heat loss in a manikin study ${ }^{57}$ and also provides external warming. The HPMK is available commercially.

Recommendation. The HPMK can be used as a convenient and effective means of preventing heat loss and providing active external rewarming (1C).

\section{Protection of cold skin}

Cold skin is very susceptible to injury from pressure or heat. ${ }^{58}$ There have been anecdotal reports of burns associated with the use of a hot water bottle with lukewarm water applied directly to hypothermic skin ${ }^{59}$ and with use of the HPMK. ${ }^{57}$ 
Recommendation. Avoid localized pressure to cold skin. Heat should never be applied directly to the skin. A barrier should be used to prevent burning the skin when using chemical or electrical heat pads or warm water bottles (1C).

\section{Do not use small chemical heat packs for rewarming}

Small chemical heat packs (eg, those used for hand and foot warming) do not provide sufficient heat to affect core temperature. In addition, the high surface temperature of small chemical heat packs creates a risk of thermal burns.

Recommendation. Do not use small chemical heat packs for rewarming a hypothermic patient (1B). Small chemical heat packs can be used to prevent local cold injury to the hands and feet during treatment and transport (1C).

\section{Heated humidified oxygen}

Although heated humidified oxygen prevents respiratory heat loss, the respiratory tract allows limited heat exchange. Heated humidified oxygen is not effective as a solitary rewarming method, ${ }^{26-28}$ but can be used as an adjunct in combination with other methods. ${ }^{26}$ Use of heated humidified oxygen has the potential to cause facial burns. ${ }^{28}$

Recommendations. Heated humidified oxygen can be used in combination with other rewarming methods (2C), but should not be relied on as the only rewarming method (1B).

\section{Do not use warm showers or baths for rewarming}

A warm shower or bath markedly increases peripheral blood flow, increasing afterdrop and potentially causing hypotension. ${ }^{25,35}$ Use of a warm shower or bath, even in a patient who is mildly hypothermic, may cause cardiovascular collapse.

Recommendation. Do not use a warm shower or bath for rewarming, even if a patient appears to be only mildly hypothermic (1C).

\section{Distal limb warming}

Distal limb warming in $42^{\circ} \mathrm{C}$ to $45^{\circ} \mathrm{C}$ water to the elbows and knees is effective in warming alert mildly hypothermic patients. ${ }^{8}$ This method works by opening arteriovenous anastomoses in the hands and feet, causing increased return flow of warmed blood directly from the arms and legs to the core. This is an exception to the general rule that peripheral rewarming is contraindicated in hypothermic patients. Because the warmed superficial venous blood bypasses the cold arteries in the extremities there is little countercurrent heat exchange. In the one laboratory study that used this method, the afterdrop was less than the afterdrop for shivering. Distal limb rewarming in water is difficult to apply during out-of-hospital transport. It was designed for use on ships.

Recommendation. Distal limb warming to the elbows and knees in $42^{\circ} \mathrm{C}$ to $45^{\circ} \mathrm{C}$ water can be used for rewarming a patient with mild hypothermia (1C).

\section{Rewarming during transport}

It is difficult to rewarm a patient during transport. A randomized, controlled study of care in helicopter and ground advanced life support (ALS) units showed a small increase in core temperature with the use of large chemical heat pads but a decrease in core temperature with passive rewarming, reflective blankets, warm IV fluids, and warm IV fluids plus reflective blankets. ${ }^{52}$

Forced-air warming, usually with an air-filled plastic baffled blanket with continuous heated airflow through perforations in the bottom of the blanket, is an effective way to rewarm a hypothermic patient. ${ }^{26,60,61}$ In one study, the afterdrop with forced-air warming was less than with shivering. ${ }^{62}$ Forced-air warming is more effective and more practical than a liquid-filled heating blanket.

Recommendations. Forced-air warming should be used during air or ground transport, if available (1A). If forced-air warming is not available, use of heat pads, including the HPMK, can be continued. Care must be take to prevent $\mathrm{CO}$ buildup with the charcoal HeatPac in a ground ambulance; this can be done by igniting the device outside the vehicle, bringing it inside only after initial smoke production subsides, ventilating the vehicle compartment, and monitoring CO (1C). HeatPac should not be used in an aircraft (1C).

\section{Temperature in air or ground ambulances}

The ideal temperature for patient compartments in ambulances is at least $28^{\circ} \mathrm{C}$, the temperature at which unclothed resting normothermic humans will neither gain nor lose heat. ${ }^{1}$ Warming the patient compartment will protect patients from further heat loss when exposed for monitoring or other procedures. However, an air temperature of $28^{\circ} \mathrm{C}$ is usually uncomfortably hot for pilots, drivers, and medical providers. A slightly cooler temperature of $24^{\circ} \mathrm{C}$ will still limit heat loss and is better tolerated by ambulance personnel.

Recommendation. Patient compartments in ground and air ambulances should be heated to at least $24^{\circ} \mathrm{C}$, if possible, to decrease further heat loss (1C). 
Treatment of cold-stressed patients who are not hypothermic

A cold patient who is alert and shivering but who has adequate energy reserves and is not hypothermic is at low risk for afterdrop or circumrescue collapse.

Recommendation. A cold-stressed patient who is not hypothermic does not need to be kept horizontal. The patient may be allowed to remove his or her own wet clothing and to put on dry clothing without shelter, if necessary. The patient may be allowed to rest in a sitting position, to eat and drink to maintain energy reserves and hydration, and may move or keep moving, if necessary (panel consensus).

\section{RESUSCITATION OF HYPOTHERMIC PATIENTS}

Decision to resuscitate hypothermic patients without signs of life

Hypothermic patients have survived with normal neurologic function even after cardiac arrest. ${ }^{18,63-65}$ Many of the usual indicators of death, such as fixed, dilated pupils and apparent rigor mortis are unreliable in hypothermic patients. ${ }^{63,64}$ Dependent lividity is also said to be an unreliable indicator of death in hypothermia, but evidence is lacking.

Recommendations. Fixed, dilated pupils, apparent rigor mortis, and dependent lividity are not contraindications to resuscitation of a severely hypothermic patient (1 A for fixed, dilated pupils and apparent rigor mortis; $2 \mathrm{C}$ for dependent lividity). If there are no contraindications to cardiopulmonary resuscitation (CPR), rescuers should not give up hope and should attempt resuscitation (1A).

\section{Contraindications to resuscitation of hypothermic patients}

The aphorism that "no one is dead until they are warm and dead" is based on the difficulty of diagnosing death in a hypothermic patient in the field. However, some patients really are cold and dead. General contraindications to attempted resuscitation in the field include obvious fatal injuries, such as decapitation, open head injury with loss of brain matter, truncal transection, incineration, or a chest wall that is so stiff that compressions are not possible. ${ }^{66}$

Recommendation. Do not attempt to resuscitate a patient with obvious fatal injuries or whose chest wall is too stiff for compressions (1A).

\section{Contraindications to resuscitation of avalanche victims}

Avalanche victims who have been buried for 35 minutes or longer with an airway that is definitely obstructed by snow or ice have died from asphyxia and cannot be successfully resuscitated (please see Avalanche section, below). ${ }^{67}$

Recommendation. Do not attempt resuscitation in an avalanche victim buried for 35 minutes or longer with an airway that is definitely obstructed by snow or ice $(1 \mathrm{~A})$.

\section{Indication for cardiopulmonary resuscitation}

CPR is only indicated in cardiac arrest. CPR is contraindicated if there are signs of life. In a hypothermic patient in the out-of-hospital setting, signs of life may be very difficult to detect. Heart rate can be very slow and pulses can be faint and hard to palpate. The traditional method of checking a pulse by trying to feel the pulse with a finger placed over the presumed location of an artery is limited by cold. Cold fingers have decreased sensitivity to tactile stimuli. Breathing can be very slow and shallow, but may be detectible in the absence of palpable pulses. ${ }^{20}$ If cardiac monitoring is not available, the diagnosis of cardiac arrest can be difficult.

Recommendation. Rescuers should make every effort to move the patient to a warm setting, such as a ground or air ambulance or a medical facility where cardiac monitoring is available to guide resuscitation and to start rewarming (1C).

Before starting CPR, feel for a carotid pulse for 1 minute. If there is no detectible pulse after 1 minute, start $\mathrm{CPR}$, including rescue breathing (1C).

\section{Electrocardiographic monitoring}

Electrocardiographic monitoring is the best way to diagnose cardiac arrest in the field. An organized rhythm without detectible pulses may be pulseless electrical activity (PEA) or may be a perfusing rhythm with very weak pulses. Starting CPR in a hypothermic patient with an organized cardiac rhythm carries a risk of causing VF that would convert a perfusing rhythm to a nonperfusing rhythm. If end-tidal $\mathrm{CO}_{2}\left(\mathrm{ETCO}_{2}\right)$ monitoring is available, lack of waveform indicates lack of circulation or absence of metabolism. ${ }^{11}$ If ultrasound is available, echocardiography can be used to determine whether there are cardiac contractions corresponding to the electrical activity. ${ }^{11}$

Recommendation. CPR should be started if a nonperfusing rhythm, including ventricular tachycardia (VT), VF, or asystole, is detected. If there is a cardiac rhythm with organized QRS complexes (other than VT), CPR should not be performed (1C) unless $\mathrm{ETCO}_{2}$ monitoring confirms lack of perfusion or echocardiography shows that there are no cardiac contractions corresponding to electrical activity (1B). 


\section{Automated external defibrillator (AED)}

If an automated external defibrillator (AED) is available that has a cardiac monitor, it can be used for cardiac monitoring. An AED can also be used for diagnosis if it has no cardiac monitor. The cardiac rhythms that may benefit from cardioversion or defibrillation ("shockable rhythms") are VT and VF. VT is rare during moderate or severe hypothermia. The instruction that shock is advised means that the rhythm is VT or VF. The instruction "no shock advised" on an AED without monitoring capability can mean that the rhythm is asystole or an organized rhythm, which may be PEA.

Recommendation. If shock is advised by the AED, attempt defibrillation and start CPR. If no shock is advised on an AED, no carotid pulse is found after palpating for at least 1 minute, normal breathing or other signs of life are not observed, and ultrasound is not available to verify cardiac activity or pulses, start CPR (1C).

\section{Delaying $C P R$, intermittent $C P R$. and prolonged $C P R$}

Cooling reduces resting oxygen consumption of most human tissue by about $6 \%$ per $1{ }^{\circ} \mathrm{C}$ decrease with a greater decrease in brain tissue. Hypothermia preferentially protects the brain from hypoxia. At a core temperature of $28^{\circ} \mathrm{C}$. whole body oxygen consumption is about $50 \%$ of normal ${ }^{1}$ whereas brain oxygen consumption can be reduced to about $35 \%$ of normal. ${ }^{7}$ At very low core temperatures the brain can tolerate more than 30 minutes of circulatory arrest. ${ }^{11,41}$ There are many cases of full neurologic recovery, even after extended periods of cardiac arrest as long as 8 hours 40 minutes $^{68}$ in persons who did not have asphyxia before they became hypothermic. Severely hypothermic patients have been resuscitated with good neurologic status even after as long as 6 hours 30 minutes of CPR. ${ }^{18,68-71}$ Prolonged cardiac arrest in severely hypothermic patients does not necessarily cause brain injury as it does in normothermic patients.

The classic teaching is that CPR must be started promptly and continued without interruption until return of spontaneous circulation (ROSC) can be established. This is not the case in patients with severe hypothermia. In one case report a hypothermic avalanche victim was successfully resuscitated with complete neurologic recovery although CPR was not started for 15 minutes after a monitored cardiac arrest. ${ }^{18}$ In another case report an avalanche victim was extricated apneic and pulseless after a 5-hour burial in a crevasse. No attempt was made to resuscitate the patient, but he was flown to a nearby hospital where ECG showed asystole. CPR was started 70 minutes after rescue. The patient made a full neurologic recovery. ${ }^{41}$ A third case report described successful resuscitation with good neurologic recovery of a hypothermic patient in cardiac arrest who was treated during evacuation with CPR in a stationary litter for 1-minute periods alternating with 1-minute periods of being carried without $\mathrm{CPR} .^{70}$

Recommendation. In patients with severe or profound hypothermia, CPR can be delayed ("scoop and run") and can be given intermittently during evacuation if it is not technically possible or safe to perform continuous CPR (1C). CPR can be given for several hours, if necessary (1B).

\section{No cutoff temperature for resuscitation}

The lowest known core temperature from which a patient with accidental hypothermia has been successfully resuscitated is $13.7^{\circ} \mathrm{C}$. $^{72}$ The lowest core temperature ever induced therapeutically is $9{ }^{\circ} \mathrm{C} .{ }^{73}$ Both patients survived neurologically intact. Unlike accidental hypothermia, induced hypothermia for cardiac or vascular surgery, usually to $10^{\circ} \mathrm{C}$, is a very controlled situation. The lowest temperature from which humans with accidental hypothermia can be successfully resuscitated is not known. A cutoff of $10^{\circ} \mathrm{C}$ has been proposed. Although it is unlikely that resuscitation from accidental hypothermia of less than $10^{\circ} \mathrm{C}$ will be successful with currently existing methods, there is no compelling evidence that there is a lower bound for successful resuscitation.

Recommendation. If there is no contraindication to CPR and no indication to terminate CPR, continue resuscitation attempts in a patient even if the core temperature is below $10^{\circ} \mathrm{C}$ measured by an esophageal probe in the lower third of the esophagus (2C).

\section{Low-amplitude QRS complexes in hypothermia}

In hypothermic patients the amplitude of the QRS complexes may be decreased. ${ }^{9}$

Recommendation. If a cardiac monitor is available, use maximal amplification to search for QRS complexes (1C).

\section{Initial defibrillation in hypothermia}

Defibrillation is only indicated for a "shockable" rhythm (pulseless VT or VF). An AED will only advise a shock if the rhythm is VT or VF. Current resuscitation guidelines recommend a single shock at maximal power for a patient whose core temperature is below $30^{\circ} \mathrm{C}$. $^{11,17,74}$

Recommendation. If a monitor or defibrillator shows VT or VF or if shock is advised by an AED in 
a patient whose core temperature is thought to be below $30^{\circ} \mathrm{C}$, give a single shock at maximal power (1C).

\section{Repeat defibrillation attempts in hypothermia}

Patients have been successfully defibrillated at core temperatures below $26^{\circ} \mathrm{C}^{75-77}$ If defibrillation below $30^{\circ} \mathrm{C}$ is unsuccessful, further shocks after rewarming to temperatures less than $30^{\circ} \mathrm{C}$ may be successful and may be justified. Below $30^{\circ} \mathrm{C}$, defibrillation is less likely to be successful than above $30^{\circ} \mathrm{C}$. Defibrillation in a patient whose core temperature has reached $30^{\circ} \mathrm{C}$ should follow guidelines for normothermic patients. ${ }^{11}$

Recommendations. Wait until a patient has been rewarmed at least $1^{\circ} \mathrm{C}$ to $2^{\circ} \mathrm{C}$ or to $30^{\circ} \mathrm{C}$ before attempting further shocks (2C). Once the core temperature reaches $30^{\circ} \mathrm{C}$, follow defibrillation guidelines for normothermic patients (1C).

\section{CPR technique in hypothermia}

A hypothermic patient will have a stiff chest wall that limits the effectiveness of chest compressions and bag valve mask ventilation. Myocardial and pulmonary compliance are also markedly reduced in severe hypothermia. During hypothermic cardiac arrest with $\mathrm{CPR}^{78}$ in a swine model, the cardiac output, cerebral blood flow, and myocardial blood flow averaged 50\%, 55\%, and $31 \%$, respectively, of those achieved during normothermic closed-chest compressions. However, metabolic demands are also decreased.

Recommendation. For cardiac arrest in a hypothermic patient, deliver chest compressions at the same rate as in normothermic patients (1C).

Ventilation in hypothermia without an advanced airway

Hyperventilation has many potentially ill effects in hypothermia, including decreased cerebral blood flow. As shown in the swine model, ventilation without an advanced airway is limited by decreased thoracic compliance. ${ }^{78}$ If available, $\mathrm{ETCO}_{2}$ monitoring can be used to prevent hyperventilation.

Recommendation. In the absence of $\mathrm{ETCO}_{2}$ monitoring, deliver ventilations at the same rate recommended for a normothermic patient, ${ }^{11,17}$ unless an advanced airway is in place (see below) (2C).

\section{Ventilation in hypothermia with advanced airway}

If the patient is intubated or has a supraglottic device, ventilations are more effective than in a patient without advanced airway management.

Recommendation. In a patient with an advanced airway, if $\mathrm{ETCO}_{2}$ monitoring is not available, deliver ventilations at half the rate recommended for a normothermic patient to avoid hyperventilation (1C).

\section{Management of $\mathrm{ETCO}_{2}$}

$\mathrm{ETCO}_{2}$ monitoring can be used to keep $\mathrm{ETCO}_{2}$ in the normal range. This range depends on altitude.

Recommendation. If $\mathrm{ETCO}_{2}$ monitoring is available, keep $\mathrm{ETCO}_{2}$ within the normal range. In rescues at altitudes above $1200 \mathrm{~m}$, ALS personnel should be aware of the normal range of $\mathrm{ETCO}_{2}$ at a given altitude (1C).

\section{Mechanical chest compressions}

Chest compressions can be performed manually or mechanically. Manual chest compressions can be difficult to perform effectively during transport. $^{70}$ Mechanical chest compressions can be performed effectively and for a prolonged time during transport. High-quality CPR, performed manually or mechanically, can be used as a temporizing measure before establishing extracorporeal circulation (ECC). ${ }^{79}$

Recommendation. High-quality CPR can be performed effectively during prolonged transport using a mechanical device (1C).

\section{Airway management in hypothermia}

The principles of airway management are the same in a hypothermic patient as in a normothermic patient. In a patient who is not breathing spontaneously or who is breathing spontaneously but not protecting the airway because of a decreased level of consciousness, advanced airway management with endotracheal intubation or use of a supraglottic airway device is indicated to provide adequate ventilation and to protect against aspiration. ${ }^{11,80}$ Although there are case reports of VF occurring during endotracheal intubation of a hypothermic patient, ${ }^{21,42,81,82}$ this is an uncommon complication. In a multicenter study, 117 hypothermic patients were intubated endotracheally after preoxygenation with $100 \%$ oxygen, without any induced dysrhythmias. ${ }^{83}$

Recommendations. The advantages of advanced airway management outweigh the risk of causing $\mathrm{VF}$ (1C). A nasogastric or orogastric tube should also be placed to decompress the stomach, after the airway is secured (1C).

Practical considerations. Rapid-sequence intubation with paralysis may not be effective if the paralytic agent is unable to overcome the trismus produced by profound hypothermia. Fiberoptic intubation or cricothyroidotomy may be required to place an endotracheal tube if cold-induced trismus prevents laryngoscopy. Use of a supraglottic device may be preferable to endotracheal 
intubation in these conditions. Overinflation of an endotracheal tube or supraglottic device cuff with cold air should be avoided because the air inside the cuff will expand as the victim rewarms, potentially kinking the tube or rupturing the cuff.

Use of anesthetic and neuromuscular blocking agents in hypothermia

At low core temperatures drug metabolism is decreased; anesthesia and neuromuscular blockade are prolonged. ${ }^{84-86}$

Recommendation. Below a core temperature of $30^{\circ} \mathrm{C}$, dosages of anesthetic and neuromuscular blocking agents should be lowered and intervals extended according to the degree of hypothermia. Current data are insufficient to recommend specific protocols (1C).

\section{Use of supplemental oxygen}

Oxygen extraction is not a limiting factor in survival from hypothermia at sea level. ${ }^{87}$

Recommendation. A hypothermic patient may receive supplemental oxygen, especially at altitudes greater than $2500 \mathrm{~m}$. There is potential benefit and no known harm (1C).

\section{Circulatory access in hypothermia}

Obtaining IV access is often difficult in hypothermic patients. Intraosseous (IO) access is fast and reliable. Because the myocardium is irritable in hypothermia, catheters that contact the heart may cause dysrhythmias. Internal jugular or subclavian central lines that extend into the right atrium are contraindicated, unless a short catheter is inserted. There is a risk of causing VF if the wire used during placement of a central venous catheter using the Seldinger technique is advanced into the heart. Care should be taken not to advance the wire too far. The femoral vein approach allows central venous access without the danger of inducing dysrhythmias, but may be difficult in the field. Unsuccessful attempts often cause hematomas.

Recommendations. If circulatory access cannot immediately be obtained with a peripheral IV catheter, access should be obtained by the IO method (1C). Central venous access can be obtained using a femoral line if no other option is available (1C).

\section{Volume replacement in hypothermia}

Circulating blood volume in moderate and severe hypothermia is reduced. ${ }^{8,87}$ During rewarming, vasoconstriction that previously limited the vascular space is abolished. Volume should be replaced to avoid severe volume depletion with resultant shock, while avoiding administration of fluid sufficient to cause volume overload. To prevent further core temperature cooling, IV or IO fluid should be warmed to at least $40^{\circ} \mathrm{C}$ and preferably to $42^{\circ} \mathrm{C}$. In the field, IV or IO bags and tubes should be insulated. Fluid warmers, preferably commercial products that have been proven effective, should be used. Because the effective perfused mass (thermal core) is decreased in hypothermia as a result of intense peripheral vasoconstriction, ${ }^{8}$ administration of fluid warmed to $40^{\circ} \mathrm{C}$ to $42^{\circ} \mathrm{C}$ may help increase core temperature. Because metabolism is depressed, glucose-containing fluid is not essential. The fluid of choice for volume replacement is normal saline. Lactated Ringer's solution should not be used in a hypothermic patient because the cold liver cannot metabolize lactate. ${ }^{1}$ Some clinicians use a mixture of crystalloid and colloid. ${ }^{1}$

Recommendation. Resuscitate a hypothermic patient with normal saline warmed to $40^{\circ} \mathrm{C}$ to $42^{\circ} \mathrm{C}$ given IV or IO. Use caution to prevent volume overload (1B).

\section{Fluid management in hypothermia}

Giving fluids in boluses, as rapidly as possible, rather than by continuous infusion will alleviate problems with cooling of fluid or freezing of lines, which can occur even if lines are insulated. The ideal method is to salinelock the line when there will be a long pause after a bolus, if provider workload permits. Boluses of $500 \mathrm{~mL}$ can be titrated to maintain adequate systolic blood pressure, depending on the degree of hypothermia. There is no available evidence to quantify a target systolic blood pressure.

Recommendations. When practical, fluids should be given as boluses rather than by continuous infusion (1C). The goal of fluid administration should be to maintain systolic blood pressure at a level that provides adequate perfusion, depending on the degree of hypothermia (1C).

\section{Use of exogenous glucose and insulin in hypothermia}

Hypoglycemia and hyperglycemia have been reported in hypothermia. ${ }^{76,88}$ Point-of-care glucose testing is routine in patients with an altered level of consciousness, but may not be available in an out-of-hospital setting. Hyperglycemia has not been shown to be deleterious in hypothermic patients. ${ }^{76}$

Recommendation. Glucose should be administered to a hypothermic patient who is hypoglycemic (1A). Insulin is not initially indicated for hyperglycemia (1B). If glucose testing is not available, IV glucose can be administered empirically to a hypothermic patient with altered mental status (1C). 
Effects of vasoactive and antidysrhythmic drugs in hypothermia

There is limited evidence regarding drug effects in hypothermic cardiac arrest in humans. Most of the evidence comes from animal studies. ${ }^{89}$ The cold heart has long been considered to be unresponsive to vasopressor or antiarrhythmic medications, although some animal studies have suggested otherwise. In a study of hypothermic dogs, the use of epinephrine increased coronary perfusion pressure (CPP) and ROSC after defibrillation. ${ }^{90}$ In a hypothermic pig study, vasopressin increased CPP with active compressiondecompression CPR using an impedance threshold valve, but not with standard CPR. ${ }^{91}$ Vasopressin improved ROSC and 1-hour survival after defibrillation in a study of hypothermic pigs. ${ }^{92}$ There is a case report of ROSC with vasopressin after unsuccessful use of epinephrine $(2 \mathrm{mg})$ in a hypothermic patient, but the patient subsequently died of multisystem failure. ${ }^{93}$

The ideal pharmacologic approach to ventricular dysrhythmias remains unresolved. Class III agents, such as bretylium and amiodarone, are theoretically ideal because they act directly against fibrillation. Amiodarone is less effective in hypothermia than in normothermia and carries a risk of inducing torsades de pointes. ${ }^{94}$ The safety of amiodarone in hypothermia is not known. In a study of hypothermic dogs, the combination of epinephrine and amiodarone increased ROSC after defibrillation following the administration of epinephrine alone. ${ }^{90}$ Bretylium failed to increase ROSC in a study of hypothermic dogs. ${ }^{95}$ In another dog study, neither amiodarone nor bretylium improved ROSC. ${ }^{96}$ There are 2 clinical reports of resolution of VF after infusion of bretylium. ${ }^{97,98}$

Recommendation. No recommendation owing to limited evidence.

\section{Dosing of drugs in hypothermia}

In hypothermia, drug metabolism is decreased and protein binding is increased. ${ }^{1}$ Drugs given while the patient is hypothermic have little activity, but may reach toxic levels with rewarming.

Recommendations. Do not administer any vasoactive drug until the patient has been rewarmed to $30^{\circ} \mathrm{C}(1 \mathrm{C})$. To minimize the potential for toxic accumulation of medications, the usual dose can be given, but dosing intervals should be twice as long as usual when the core temperature is $30^{\circ} \mathrm{C}$ to $35^{\circ} \mathrm{C}(2 \mathrm{C})$.

\section{Transcutaneous cardiac pacing in hypothermia}

Two case reports suggest that transcutaneous pacing may be beneficial in a hypothermic patient. ${ }^{99}$ In both cases, transcutaneous pacing was instituted to increase blood pressure to facilitate arteriovenous rewarming rather than for control of heart rate.

Recommendation. Transcutaneous pacing may be beneficial in hypothermia in the setting of bradycardia with hypotension disproportionate to the core temperature (2C).

Management of atrial dysrhythmias during rewarming of a hypothermic patient

Atrial dysrhythmias in hypothermic patients during rewarming are common and resolve spontaneously once the patient has been sufficiently rewarmed. ${ }^{100}$

Recommendation. No treatment is indicated for atrial dysrhythmias in a hemodynamically stable patient during rewarming (IB).

\section{TRANSPORT AND TRIAGE}

\section{Severe trauma}

Core temperatures of $35^{\circ} \mathrm{C}$ or less are associated with decreased survival in patients with severe trauma. ${ }^{101,102}$ Severe trauma can cause acidosis and coagulopathy. In trauma patients with hemorrhagic shock, the "lethal triad" of acidosis, coagulopathy, and hypothermia is associated with multiorgan system dysfunction ${ }^{103}$ and with extremely high mortality. ${ }^{104}$

Recommendation. A severely injured patient should be treated early and aggressively with active rewarming during all phases of out-of-hospital care to prevent hypothermia (1B).

\section{Stabilizing injuries for transport}

Stabilization of injuries for transport is the same in a hypothermic patient as in a normothermic patient.

Recommendations. To prepare a patient for transport, potential spinal injuries should be stabilized ${ }^{105}$ (1C). Fractures and dislocations should be reduced as much as possible to normal anatomic configuration (1C). Open wounds should be covered (1C).

\section{CHOICE OF DESTINATION HOSPITAL FOR HYPOTHERMIC PATIENTS}

There are no published studies that have specifically analyzed transport decisions for hypothermic patients. This section is based on field observations and expert consensus, except as noted below.

Alert patients with mild hypothermia

Alert patients with mild hypothermia can be treated in the field. 
Recommendation. An uninjured patient who is completely alert and shivering may be treated without being transported to a hospital (1B).

Alert hypothermic patients with comorbidities, including trauma or asphyxia

Hypothermic patients with injuries or other medical problems should be transferred to a hospital able to manage these problems. Asphyxiated patients (from avalanche or drowning) may appear stable but are at risk for delayed complications and are likely to require a higher level of care. ${ }^{106}$

Recommendations. If injuries meet trauma criteria, a patient should be transported to a trauma center (1B). An asphyxiated patient should be transported to a hospital for observation (1B).

\section{Hypothermic patients with altered level of consciousness}

Patients with an altered level of consciousness will require active rewarming whether shivering or not. Hemodynamically unstable patients require critical care and may benefit from ECC with extracorporeal membrane oxygenation (ECMO) or cardiopulmonary bypass (CPB). ECMO is preferred to $\mathrm{CPB},{ }^{106}$ but both have been used successfully to rewarm severely hypothermic patients.

Many geographic areas do not have a hospital capable of ECC. In some cases bad weather or other factors may prevent transfer of a patient to a hospital with ECC. Hemodynamically unstable hypothermia patients, including hypothermia patients in cardiac arrest, have been successfully resuscitated with complete neurologic recovery without the use of ECC. ${ }^{69,107-109}$

Recommendations. A patient with moderate to severe hypothermia who is hemodynamically stable can be transferred to the closest hospital or other appropriate medical facility such as a rural clinic (1C).

A patient who is hemodynamically unstable or who has a core temperature less than $28^{\circ} \mathrm{C}$ should be transferred to a hospital capable of providing critical care and $\mathrm{ECC}$, if possible. If this will require significant additional time-generally more than an additional hour-of noncritical care transport the patient should first be stabilized at a closer facility (1C).

A patient in cardiac arrest should be transferred to a hospital capable of providing ECC if possible. If all other factors are equal, ECMO is preferable to CPB (1B).

In geographic regions where there is no hospital capable of providing ECC or when a hospital capable of providing ECC is not accessible, transport a patient in cardiac arrest to the closest hospital where serum potassium can be measured and where resuscitation methods not involving ECC can be attempted for a patient whose serum potassium is $12 \mathrm{mmol} / \mathrm{L}$ or less. (Please see following section for use of biochemical markers.) (1C).

Use of biochemical markers to determine whether resuscitation should be continued in a hypothermic patient without vital signs

Increased serum potassium in a hypothermic patient usually indicates that hypothermia was preceded by hypoxia. As such, it is a marker of cell lysis and death. The highest serum potassium in a patient resuscitated from hypothermia was $11.8 \mathrm{mmol} / \mathrm{L}$ in a 31 -month-old child. This level is questionable because the repeat potassium 25 minutes later was $4.8 \mathrm{mmol} / \mathrm{L}$ without mention of therapeutic intervention. ${ }^{110}$ In older patients the highest levels recorded in patients who were resuscitated were $9.5 \mathrm{mmol} / \mathrm{L}$ in a 13 -year-old ${ }^{111}$ and $7.9 \mathrm{mmol} / \mathrm{L}$ in a 34 -year-old. ${ }^{112}$

Recommendation. If an adult hypothermic patient has a potassium greater than $12 \mathrm{mmol} / \mathrm{L}, \mathrm{CPR}$ should be terminated (1B).

\section{AVALANCHE}

Asphyxia, sometimes associated with trauma or hypothermia, is the most common cause of death in avalanche burial. ${ }^{67}$ Avalanche victims who survive initially may asphyxiate as a result of rebreathing expired air, causing hypercapnia and hypoxemia, because of airway obstruction from snow or other avalanche debris, trauma, or inability to expand the chest. Survival decreases rapidly during the first 35 minutes after burial. This has been called the "asphyxial phase." A victim without a patent airway will die within the first 35 minutes. ${ }^{113} \mathrm{~A}$ victim with a patent airway may survive for longer periods. If the airway is patent, an air pocket (an open space in front of the mouth or nose) increases the chance of survival ${ }^{114}$ by delaying asphyxiation. Asphyxiation results in more severe hypothermia in an avalanche victim who is extricated alive. ${ }^{115,116}$

\section{Avalanche burial victims in cardiac arrest}

Assessment of an avalanche burial victim in cardiac arrest should include the estimated burial time or the core temperature. Core temperature may be predictive of burial time. Cooling rates as high as $9^{\circ} \mathrm{C} / \mathrm{h}$ have been reported after avalanche burial, ${ }^{18}$ but a case series found an average rate of cooling of about $3{ }^{\circ} \mathrm{C} / \mathrm{h} .{ }^{117}$ In one case report of survival after 20 hours of avalanche burial with a large air pocket, the cooling rate was $0.6^{\circ} \mathrm{C} / \mathrm{h},{ }^{118}$ 
which is similar to cooling rates observed during experimental snow burial studies on humans. ${ }^{118,119}$

Recommendations. An avalanche victim buried 35 minutes or less or with a core temperature of at least $32^{\circ} \mathrm{C}$ should receive standard resuscitation, including CPR if in cardiac arrest ${ }^{67,120}$ (1C). If there is ROSC, the victim should be transported to the nearest hospital that can manage any associated injuries (1C).

An avalanche victim who was buried more than 35 minutes or who has a core temperature less than $32^{\circ} \mathrm{C}$ and has detectable vital signs should be transported to the nearest hospital or rural clinic for active rewarming (1C). If there are no vital signs and the airway is patent, CPR should be started ${ }^{67}$ (1B).

An avalanche victim in cardiac arrest with an airway that is definitely obstructed should not be resuscitated if burial time was greater than 35 minutes or core temperature is less than $32^{\circ} \mathrm{C}^{67}$ (1C). If there is any chance that the airway was patent, a short trial of CPR is warranted (1B).

\section{Termination of resuscitation if serum potassium is more than $12 \mathrm{mmol} / \mathrm{L}$}

Avalanche burial usually causes hypoxia before hypothermia. Although it is generally not possible to measure serum potassium in the out-of-hospital setting, elevated serum potassium in a victim of avalanche burial is a useful marker of asphyxia. The highest known potassium in an avalanche victim who was resuscitated is 6.4 $\mathrm{mmol} / \mathrm{L} .{ }^{117}$ The ideal cutoff for withholding or discontinuing resuscitation is not known. A conservative upper limit is $12 \mathrm{mmol} / \mathrm{L}$ as in hypothermia without asphyxia. ${ }^{11}$

Recommendations. An avalanche victim with CPR in progress should be transported to a hospital with the capability of performing extracorporeal rewarming if possible (1B). If it is not practical for the patient to go directly to a hospital that can perform extracorporeal rewarming and serum potassium has not already been measured, the patient should be transported to a hospital or clinic capable of measuring serum potassium (1C). Resuscitation should be continued only if serum potassium is $12 \mathrm{mmol} / \mathrm{L}$ or less (1B).

\section{Conclusions}

To assist medical providers caring for patients with accidental hypothermia in the out-of-hospital setting, we have provided evidence-based recommendations for evaluation and treatment. There are several important areas of uncertainty that should be the objects of future research. These areas include the optimal methods of evaluating patients with accidental hypothermia, best treatments for patients with mild-to-moderate hypothermia, and optimal methods of resuscitating hypothermic patients in cardiac arrest.

\section{References}

1. Danzl D. Accidental hypothermia. In: Auerbach PS, ed. Wilderness Medicine 6th ed. Philadelphia, PA: Elsevier; 2012:116-142.

2. Guyatt G, Gutterman D, Baumann MH, et al. Grading strength of recommendations and quality of evidence in clinical guidelines: report from an American College of Chest Physicians task force. Chest. 2006;129:174-181.

3. Giesbrecht GG. Cold stress, near drowning and accidental hypothermia: a review. Aviat Space Environ Med. 2000;71:733-752.

4. Bristow GK, Giesbrecht GG. Contribution of exercise and shivering to recovery from induced hypothermia (31.2 degrees C) in one subject. Aviat Space Environ Med. 1988;59:549-552.

5. Giesbrecht GG, Arnett JL, Vela E, Bristow GK. Effect of task complexity on mental performance during immersion hypothermia. Aviat Space Environ Med. 1993;64(3 Pt 1): 206-211.

6. FitzGibbon T, Hayward JS, Walker D. EEG and visual evoked potentials of conscious man during moderate hypothermia. Electroencephalogr Clin Neurophysiol. 1984;58:48-54.

7. Michenfelder JD, Milde JH. The relationship among canine brain temperature, metabolism, and function during hypothermia. Anesthesiology. 1991;75:130-136.

8. Vanggaard L, Eyolfson D, Xu X, Weseen G, Giesbrecht GG. Immersion of distal arms and legs in warm water (AVA rewarming) effectively rewarms mildly hypothermic humans. Aviat Space Environ Med. 1999;70:10811088.

9. Duguid H, Simpson RG, Stowers JM. Accidental hypothermia. Lancet. 1961;278:1213-1219.

10. Giesbrecht GG. The respiratory system in a cold environment. Aviat Space Environ Med. 1995;66:890-902.

11. Soar J, Perkins GD, Abbas G, et al. European Resuscitation Council Guidelines for Resuscitation 2010 Section 8. Cardiac arrest in special circumstances: electrolyte abnormalities, poisoning, drowning, accidental hypothermia, hyperthermia, asthma, anaphylaxis, cardiac surgery, trauma, pregnancy, electrocution. Resuscitation. 2010;81:1400-1433.

12. Durrer B, Brugger H, Syme D. International Commission for Mountain Emergency Medicine. The medical on-site treatment of hypothermia: ICAR-MEDCOM recommendation. High Alt Med Biol. 2003;4:99-103.

13. Zafren K, Giesbrecht G. State of Alaska Cold Injuries Guidelines Juneau, AK: State of Alaska; 2014.

14. Strapazzon G, Procter E, Paal P, Brugger H. Pre-hospital core temperature measurement in accidental and therapeutic hypothermia. High Alt Med Biol. 2014;15:104-111. 
15. Tikuisis P, Giesbrecht GG. Prediction of shivering heat production from core and mean skin temperatures. Eur J Appl Physiol Occup Physiol. 1999;79:221-229.

16. Giesbrecht GG. Emergency treatment of hypothermia. Emerg Med (Fremantle). 2001;13:9-16.

17. Vanden Hoek TL, Morrison LJ, Shuster M, et al. Part 12: Cardiac arrest in special situations: 2010 American Heart Association Guidelines for Cardiopulmonary Resuscitation and Emergency Cardiovascular Care. Circulation. 2010;122(18 Suppl 3):S829-S861.

18. Oberhammer R, Beikircher W, Hörmann C, et al. Full recovery of an avalanche victim with profound hypothermia and prolonged cardiac arrest treated by extracorporeal re-warming. Resuscitation. 2008;76:474-480.

19. Papenhausen M, Burke L, Antony A, Phillips JD. Severe hypothermia with cardiac arrest: complete neurologic recovery in a 4-year-old child. $J$ Pediatr Surg. 2001;36:1590-1592.

20. Feiss P, Mora C, Devalois B, Gobeaux R, Christides C. Accidental deep hypothermia and circulatory arrest. Treatment with extracorporeal circulation [in French]. Ann Fr Anesth Reanim. 1987;6:217-218.

21. Baumgartner FJ, Janusz MT, Jamieson WR, Winkler T, Burr LH, Vestrup JA. Cardiopulmonary bypass for resuscitation of patients with accidental hypothermia and cardiac arrest. Can J Surg. 1992;35:184-187.

22. Pasquier M, Zurron N, Weith B, et al. Deep accidental hypothermia with core temperature below $24^{\circ} \mathrm{C}$ presenting with vital signs. High Alt Med Biol. 2014;15:58-63.

23. Stoner HB. Thermoregulation after injury. Adv Exp Med Biol. 1972;33(0):495-499.

24. Giesbrecht GG, Goheen MS, Johnston CE, Kenny GP, Bristow GK, Hayward JS. Inhibition of shivering increases core temperature afterdrop and attenuates rewarming in hypothermic humans. J Appl Physiol. 1997;83:1630-1634.

25. Hayward JS, Eckerson JD, Kemna D. Thermal and cardiovascular changes during three methods of resuscitation from mild hypothermia. Resuscitation. 1984;11:21-33.

26. Goheen MS, Ducharme MB, Kenny GP, et al. Efficacy of forced-air and inhalation rewarming by using a human model for severe hypothermia. J Appl Physiol. 1997;83:1635-1640.

27. Mekjavic IB, Eiken O. Inhalation rewarming from hypothermia: an evaluation in -20 degrees C simulated field conditions. Aviat Space Environ Med. 1995;66:424-429.

28. Sterba JA. Efficacy and safety of prehospital rewarming techniques to treat accidental hypothermia. Ann Emerg Med. 1991;20:896-901.

29. Walpoth BH, Galdikas J, Leupi F, Muehlemann W, Schlaepfer P, Althaus U. Assessment of hypothermia with a new "tympanic" thermometer. J Clin Monit. 1994;10: 91-96.

30. Kimberger O, Cohen D, Illievich U, Lenhardt R. Temporal artery versus bladder thermometry during perioperative and intensive care unit monitoring. Anesth Analg. 2007;105:1042-1047.
31. Gunga HC, Werner A, Stahn A, et al. The Double Sensor-a non-invasive device to continuously monitor core temperature in humans on earth and in space. Respir Physiol Neurobiol. 2009;169(Suppl 1): S63-S68.

32. Kimberger O, Thell R, Schuh M, Koch J, Sessler DI, Kurz A. Accuracy and precision of a novel non-invasive core thermometer. Br J Anaesth. 2009;103:226-231.

33. Giesbrecht GG, Bristow GK. A second postcooling afterdrop: more evidence for a convective mechanism. J Appl Physiol. 1992;73:1253-1258.

34. Golden FS, Hervey GR. The mechanism of the after-drop following immersion hypothermia in pigs [proceedings]. J Physiol. 1977;272(1):26P-27P.

35. Romet TT. Mechanism of afterdrop after cold water immersion. J Appl Physiol. 1988;65:1535-1538.

36. Fox JB, Thomas F, Clemmer TP, Grossman M. A retrospective analysis of air-evacuated hypothermia patients. Aviat Space Environ Med. 1988;59(11 Pt 1): 1070-1075.

37. Stoneham MD, Squires SJ. Prolonged resuscitation in acute deep hypothermia. Anaesthesia. 1992;47:784-788.

38. Golden FS, Hervey GR, Tipton MJ. Circum-rescue collapse: collapse, sometimes fatal, associated with rescue of immersion victims. J $R$ Nav Med Serv. 1991;77:139-149.

39. Giesbrecht GG, Bristow GK. The convective afterdrop component during hypothermic exercise decreases with delayed exercise onset. Aviat Space Environ Med. 1998;69:17-22.

40. Giesbrecht GG, Hayward JS. Problems and complications with cold-water rescue. Wilderness Environ Med. 2006; 17:26-30.

41. Althaus U, Aeberhard P, Schüpbach P, Nachbur BH, Mühlemann W. Management of profound accidental hypothermia with cardiorespiratory arrest. Ann Surg. 1982;195:492-495.

42. Osborne L, Kamal El-Din AS, Smith JE. Survival after prolonged cardiac arrest and accidental hypothermia. Br Med J (Clin Res Ed). 1984;289:881-882.

43. Lee CH, Van Gelder C, Burns K, Cone DC. Advanced cardiac life support and defibrillation in severe hypothermic cardiac arrest. Prehosp Emerg Care. 2009;13: 85-89.

44. Henriksson O, Lundgren P, Kuklane K, Holmér I, Bjornstig U. Protection against cold in prehospital care - thermal insulation properties of blankets and rescue bags in different wind conditions. Prehosp Disaster Med. 2009;24:408-415.

45. Thomassen $\varnothing$, Færevik H, Østerås $\varnothing$, et al. Comparison of three different prehospital wrapping methods for preventing hypothermia - a crossover study in humans. Scand J Trauma Resusc Emerg Med. 2011;19:41.

46. Hayward JS, Collis M, Eckerson JD. Thermographic evaluation of relative heat loss areas of man during cold water immersion. Aerosp Med. 1973;44:708-711. 
47. Pretorius T, Bristow GK, Steinman AM, Giesbrecht GG. Thermal effects of whole head submersion in cold water on nonshivering humans. J Appl Physiol. 2006;101:669-675.

48. Henriksson O, Lundgren P, Kuklane K, Holmér I, Naredi $\mathrm{P}$, Bjornstig U. Protection against cold in prehospital care: evaporative heat loss reduction by wet clothing removal or the addition of a vapor barrier - a thermal manikin study. Prehosp Disaster Med. 2012;27:53-58.

49. Iampietro PF, Vaughan JA, Goldman RF, Kreider MB, Masucci F, Bass DE. Heat production from shivering. J Appl Physiol. 1960;15:632-634.

50. Giesbrecht GG, Sessler DI, Mekjavić IB, Schroeder M, Bristow GK. Treatment of mild immersion hypothermia by direct body-to-body contact. J Appl Physiol. 1994;76: 2373-2379.

51. Hultzer MV, Xu X, Marrao C, Bristow G, Chochinov A, Giesbrecht GG. Pre-hospital torso-warming modalities for severe hypothermia: a comparative study using a human model. CJEM. 2005;7:378-386.

52. Watts DD, Roche M, Tricarico R, et al. The utility of traditional prehospital interventions in maintaining thermostasis. Prehosp Emerg Care. 1999;3:115-122.

53. Lundgren $P$, Henriksson $\mathrm{O}$, Naredi $\mathrm{P}$, Björnstig U. The effect of active warming in prehospital trauma care during road and air ambulance transportation - a clinical randomized trial. Scand J Trauma Resusc Emerg Med. 2009;19:59.

54. Lundgren JP, Henriksson O, Pretorius T, et al. Field torso-warming modalities: a comparative study using a human model. Prehosp Emerg Care. 2009;13:371-378.

55. Giesbrecht GG, Bristow GK, Uin A, Ready AE, Jones RA. Effectiveness of three field treatments for induced mild (33.0 degrees C) hypothermia. J Appl Physiol. 1987;63:2375-2379.

56. Ducharme MB, Tikuisis P. Role of blood as heat source or sink in human limbs during local cooling and heating. J Appl Physiol. 1994;76:2084-2094.

57. Allen PB, Salyer SW, Dubick MA, Holcomb JB, Blackbourne LH. Preventing hypothermia: comparison of current devices used by the US Army in an in vitro warmed fluid model. J Trauma. 2010;69(Suppl 1):S154-S161.

58. Steinman AM. Cardiopulmonary resuscitation and hypothermia. Circulation. 1986;74(6 Pt 2):IV29-IV32.

59. Giesbrecht GG, Steinman AM. Immersion into cold water. In: Auerbach PS, ed. Wilderness Medicine 6th ed. Philadelphia, PA: Elsevier; 2012:143-170.

60. Ducharme MB, Giesbrecht GG, Frim J, et al. Forced-air rewarming in -20 degrees $\mathrm{C}$ simulated field conditions. Ann N Y Acad Sci. 1997;813:676-681.

61. Steele MT, Nelson MJ, Sessler DI, et al. Forced air speeds rewarming in accidental hypothermia. Ann Emerg Med. 1996;27:479-484.

62. Giesbrecht GG, Schroeder M, Bristow GK. Treatment of mild immersion hypothermia by forced-air warming. Aviat Space Environ Med. 1994;65:803-808.

63. Leitz KH, Tsilimingas N, Güse HG, Meier P, Bachmann HJ. Accidental drowning with extreme hypothermia- rewarming with extracorporeal circulation [in German]. Chirurg. 1989;60:352-355.

64. Ko CS, Alex J, Jeffries S, Parmar JM. Dead? Or just cold: profoundly hypothermic patient with no signs of life. Emerg Med J. 2002;19:478-479.

65. Walpoth BH, Walpoth-Aslan BN, Mattle HP, et al. Outcome of survivors of accidental deep hypothermia and circulatory arrest treated with extracorporeal blood warming. N Engl J Med. 1997;337:1500-1505.

66. Paal P, Milani M, Brown D, Boyd J, Ellerton J. Termination of cardiopulmonary resuscitation in mountain rescue. High Alt Med Biol. 2012;13:200-208.

67. Brugger H, Durrer B, Elsensohn F, et al. Resuscitation of avalanche victims: evidence-based guidelines of the International Commission for Mountain Emergency Medicine (ICAR MEDCOM): intended for physicians and other advanced life support personnel. Resuscitation. 2012;84:539-546.

68. Meyer M, Pelurson N, Khabiri E, Siegenthaler N, Walpoth BH. Sequela-free long-term survival of a 65 year-old woman after 8 hours and 40 minutes of cardiac arrest from deep accidental hypothermia. J Thorac Cardiovasc Surg. 2014;147:e1-e2.

69. Lexow K. Severe accidental hypothermia: survival after 6 hours 30 minutes of cardiopulmonary resuscitation. Arctic Med Res. 1991;50(Suppl 6):112-114.

70. Boue Y, Lavolaine J, Bouzat P, Matraxia S, Chavanon O, Payen JF. Neurologic recovery from profound accidental hypothermia after 5 hours of cardiopulmonary resuscitation. Crit Care Med. 2014;42:e167-e170.

71. Hilmo J, Naesheim T, Gilbert M. "Nobody is dead until warm and dead": prolonged resuscitation is warranted in arrested hypothermic victims also in remote areas-a retrospective study from northern Norway. Resuscitation. 2014;85:1204-1211.

72. Gilbert M, Busund R, Skagseth A, Nilsen PA, Solbo JP. Resuscitation from accidental hypothermia of 13.7 degrees C with circulatory arrest. Lancet. 2000;355:375-376.

73. Niazi SA, Lewis FJ. Profound hypothermia in man; report of a case. Ann Surg. 1958;147:264-266.

74. Ujhelyi MR, Sims JJ, Dubin SA. Vender J, Miller AW. Defibrillation energy requirements and electrical heterogeneity during total body hypothermia. Crit Care Med. 2001;29:1006-1011.

75. DaVee TS, Reineberg EJ. Extreme hypothermia and ventricular fibrillation. Ann Emerg Med. 1980;9:100-102.

76. Koller R, Schnider TW, Neidhart P. Deep accidental hypothermia and cardiac arrest-rewarming with forced air. Acta Anaesthesiol Scand. 1997;41:1359-1364.

77. Thomas R, Cahill CJ. Successful defibrillation in profound hypothermia (core body temperature 25.6 degrees C). Resuscitation. 2000;47:317-320.

78. Maningas PA, DeGuzman LR, Hollenbach SJ, Volk KA, Bellamy RF. Regional blood flow during hypothermic arrest. Ann Emerg Med. 1986;15:390-396.

79. Wik L, Kiil S. Use of an automatic mechanical chest compression device (LUCAS) as a bridge to establishing 
cardiopulmonary bypass for a patient with hypothermic cardiac arrest. Resuscitation. 2005;66:391-394.

80. Morrison LJ, Deakin CD, Morley PT, et al. Advanced Life Support Chapter Collaborators. Part 8: Advanced life support: 2010 International Consensus on Cardiopulmonary Resuscitation and Emergency Cardiovascular Care Science With Treatment Recommendations. Circulation. 2010;122(16 suppl 2):S345-S421.

81. Binnema R, van der Wal A, Visser C, Schepp R, Jekel L, Schröder P. Treatment of accidental hypothermia with cardiopulmonary bypass: a case report. Perfusion. 2008;23:193-196.

82. Hauty MG, Esrig BC, Hill JG, Long WB. Prognostic factors in severe accidental hypothermia: experience from the Mt. Hood tragedy. J Trauma. 1987;27:11071112.

83. Danzl DF, Pozos RS, Auerbach PS, et al. Multicenter hypothermia survey. Ann Emerg Med. 1987;16:10421055 .

84. Leslie K, Sessler DI, Bjorksten AR, Moayeri A. Mild hypothermia alters propofol pharmacokinetics and increases the duration of action of atracurium. Anesth Analg. 1995;80:1007-1014.

85. Caldwell JE, Heier T, Wright PM, et al. Temperaturedependent pharmacokinetics and pharmacodynamics of vecuronium. Anesthesiology. 2000;92:84-93.

86. Heier T, Caldwell JE. Impact of hypothermia on the response to neuromuscular blocking drugs. Anesthesiology. 2006;104:1070-1080.

87. Kondratiev TV, Flemming K, Myhre ES, Sovershaev MA, Tveita T. Is oxygen supply a limiting factor for survival during rewarming from profound hypothermia? Am J Physiol Heart Circ Physiol. 2006;291:H441-H450.

88. Strapazzon G, Nardin M, Zanon P, Kaufmann M, Kritzinger M, Brugger H. Respiratory failure and spontaneous hypoglycemia during noninvasive rewarming from $24.7^{\circ} \mathrm{C}\left(76.5^{\circ} \mathrm{F}\right)$ core body temperature after prolonged avalanche burial. Ann Emerg Med. 2012;60:193-196.

89. Wira CR, Becker JU, Martin G, Donnino MW. Antiarrhythmic and vasopressor medications for the treatment of ventricular fibrillation in severe hypothermia: a systematic review of the literature. Resuscitation. 2008;78: 21-29.

90. Wira C, Martin G, Stoner J, Margolis K, Donnino M. Application of normothermic cardiac arrest algorithms to hypothermic cardiac arrest in a canine model. Resuscitation. 2006;69:509-516.

91. Raedler C, Voelckel WG, Wenzel V, et al. Vasopressor response in a porcine model of hypothermic cardiac arrest is improved with active compressiondecompression cardiopulmonary resuscitation using the inspiratory impedance threshold valve. Anesth Analg. 2002;95:1496-1502.

92. Schwarz B, Mair P, Raedler C, Deckert D, Wenzel V, Lindner KH. Vasopressin improves survival in a pig model of hypothermic cardiopulmonary resuscitation. Crit Care Med. 2002;30:1311-1314.
93. Sumann G, Krismer AC, Wenzel V, et al. Cardiopulmonary resuscitation after near drowning and hypothermia: restoration of spontaneous circulation after vasopressin. Acta Anaesthesiol Scand. 2003;47:363-365.

94. Khan JN, Prasad N, Glancy J. Amiodarone use in therapeutic hypothermia following cardiac arrest due to ventricular tachycardia and ventricular fibrillation. Europace. 2009;11:1566-1567.

95. Elenbaas RM, Mattson K, Cole H, Steele M, Ryan J, Robinson W. Bretylium in hypothermia-induced ventricular fibrillation in dogs. Ann Emerg Med. 1984;13:994-999.

96. Stoner J, Martin G, O’Mara K, Ehlers J, Tomlanovich M. Amiodarone and bretylium in the treatment of hypothermic ventricular fibrillation in a canine model. Acad Emerg Med. 2003;10:187-191.

97. Danzl DF, Sowers MB, Vicario SJ, Thomas DM, Miller JW. Chemical ventricular defibrillation in severe accidental hypothermia. Ann Emerg Med. 1982;11:698-699.

98. Lloyd EL. Accidental hypothermia. Resuscitation. 1996;32:111-124.

99. Ho JD, Heegaard WG, Brunette DD. Successful transcutaneous pacing in 2 severely hypothermic patients. Ann Emerg Med. 2007;49:678-681.

100. Rankin AC, Rae AP. Cardiac arrhythmias during rewarming of patients with accidental hypothermia. $\mathrm{Br}$ Med J (Clin Res Ed). 1984;289:874-877.

101. Jurkovich GJ, Greiser WB, Luterman A, Curreri PW. Hypothermia in trauma victims: an ominous predictor of survival. J Trauma. 1987;27:1019-1024.

102. Martin RS, Kilgo PD, Miller PR, Hoth JJ, Meredith JW, Chang MC. Injury-associated hypothermia: an analysis of the 2004 National Trauma Data Bank. Shock. 2005;24: 114-118.

103. Beilman GJ, Blondet JJ, Nelson TR, et al. Early hypothermia in severely injured trauma patients is a significant risk factor for multiple organ dysfunction syndrome but not mortality. Ann Surg. 2009;249: 845-850.

104. Mitra B, Tullio F, Cameron PA, Fitzgerald M. Trauma patients with the 'triad of death.' Emerg Med J. 2012;29:622-625.

105. Quinn R, Williams J, Bennett B, Stiller G, Islas A, McCord S. Wilderness Medical Society. Wilderness Medical Society practice guidelines for spine immobilization in the austere environment. Wilderness Environ Med. 2013;24:241-252.

106. Ruttmann E, Weissenbacher A, Ulmer H, et al. Prolonged extracorporeal membrane oxygenation-assisted support provides improved survival in hypothermic patients with cardiocirculatory arrest. J Thorac Cardiovasc Surg. 2007;134:594-600.

107. Gruber E, Beikircher W, Pizzinini R, et al. Nonextracorporeal rewarming at a rate of 6.8 degrees $\mathrm{C}$ per hour in a deeply hypothermic arrested patient. Resuscitation. 2014;85:e119-e120.

108. Turtiainen J, Halonen J, Syväoja S, Hakala T. Rewarming a patient with accidental hypothermia and cardiac arrest 
using thoracic lavage. Ann Thorac Surg. 2014;97:21652166.

109. Roggero E, Stricker H, Biegger P. Severe accidental hypothermia with cardiopulmonary arrest: prolonged resuscitation without extracorporeal circulation [in German]. Schweiz Med Wochenschr. 1992;122:161-164.

110. Dobson JA, Burgess JJ. Resuscitation of severe hypothermia by extracorporeal rewarming in a child. $J$ Trauma. 1996;40:483-485.

111. von Segesser LK, Garcia E, Turina M. Perfusion without systemic heparinization for rewarming in accidental hypothermia. Ann Thorac Surg. 1991;52:560-561.

112. Farstad M, Andersen KS, Koller ME, Grong K, Segadal L, Husby P. Rewarming from accidental hypothermia by extracorporeal circulation. A retrospective study. Eur J Cardiothorac Surg. 2001;20:58-64.

113. Boyd J, Brugger H, Shuster M. Prognostic factors in avalanche resuscitation: a systematic review. Resuscitation. 2010;81:645-652.

114. Boué Y, Payen JF, Brun J, et al. Survival after avalanche-induced cardiac arrest. Resuscitation. 2014;85: 1192-1196.
115. Grissom CK, Radwin MI, Harmston CH. Improving survival during snow burial in avalanches. JAMA. 2000;284:1242-1243.

116. Brugger H, Sumann G, Meister R, et al. Hypoxia and hypercapnia during respiration into an artificial air pocket in snow: implications for avalanche survival. Resuscitation. 2003;58:81-88.

117. Locher T, Walpoth BH. Differential diagnosis of circulatory failure in hypothermic avalanche victims: retrospective analysis of 32 avalanche accidents [in German]. Praxis (Bern 1994). 1996;85:1275-1282.

118. Grissom CK, Radwin MI, Scholand MB, Harmston CH, Muetterties MC, Bywater TJ. Hypercapnia increases core temperature cooling rate during snow burial. J Appl Physiol. 2004;96:1365-1370.

119. Grissom CK, McAlpine JC, Harmston CH, et al. Hypercapnia effect on core cooling and shivering threshold during snow burial. Aviat Space Environ Med. 2008;79:735-742.

120. Paal P, Strapazzon G, Braun P, et al. Factors affecting survival from avalanche burial - a randomised prospective porcine pilot study. Resuscitation. 2013;84:239-243. 